\title{
The Nottingham, Leicester, Derby aircraft accident study: preliminary report three weeks after the accident
}

\author{
G Kirsh, D J A Learmonth, J P Martindale, and the Nottingham, Leicester, Derby Aircraft \\ Accident Study Group
}

At 830 pm on Sunday 8 January 1989 flight BD92, a British Midlands Boeing 737-400 from Heathrow to Belfast, crash landed near Kegworth (fig 1). The aircraft flew over the village of Kegworth and in failing to reach the runway at East Midlands airport crashed on to the Ml motorway and into the motorway embankment. The fuselage of the aircraft broke into three main sections on impact, with the tail section breaking off and rotating through $90^{\circ}$ to end up vertical (fig 2). The authorities were aware of an impending incident as the captain had reported an engine failure and had requested permission for an emergency landing at East Midlands airport. The emergency services had already been mobilised and were soon at the scene of the crash. Many bystanders at the motorway also began the task of rescuing the survivors.

The flight was carrying 126 passengers and crew, of whom 38 died at the site of the accident, leaving 88 initial survivors - a comparatively larger number for an aircraft accident. As these people were evacuated they were transported to one of the three main hospitals nearby: University Hospital, Nottingham, where 40 patients were received; Leicester Royal Infirmary, where 21 patients were received; and Derbyshire Royal Infirmary, where 25 patients were received. A further two patients were transferred to Mansfield and District Hospital, a small district general hospital. The first survivors taken from the scene were all taken to Nottingham as it was initially thought that the roads to Derby and Leicester were closed. All neurosurgical cases were to be diverted to Nottingham, where the local neurosurgical unit is based. At all three hospitals a "major incident" protocol was activated and extra staff, both medical and non-medical, were mobilised.

University Hospital, Nottingham NG7 2UH G Kirsh, MB, senior orthopaedic registrar

Leicester Royal Infirmary, Leicester LE1 5WW D J A Learmonth, FRCs, orthopaedic registrar

Derbyshire Royal Infirmary, Derby DE1 1DP J P Martindale, FRCS, orthopaedic registrar

Correspondence and requests for reprints to: Professor W A Wallace, Department of Orthopaedic and Accident Surgery, University Hospital, Nottingham NG7 2UH.

\section{University Hospital, Nottingham}

In Nottingham 45 porters were summoned, and most stayed on through the night. Many staff rallied to their hospital to help as soon as they heard the news, and there was never a shortage of help. All 10 orthopaedic consultants and all consultants in accident and emergency medicine and representatives of other relevant specialties were on hand within 30 minutes after the crash, as well as many registrars. The first of the patients arrived at $9 \mathrm{pm}$, and were the first survivors to be taken from the aircraft. They were rapidly resuscitated and assessed, with those needing immediate operation being taken to one of the eight operating theatres that were to be active throughout the night. Eleven patients were operated on that night, with 38 procedures being performed. Several other patients with multiple injuries were taken from the accident and emergency department to the intensive care unit for resuscitation and monitoring. Twelve patients were admitted to the intensive care unit; after

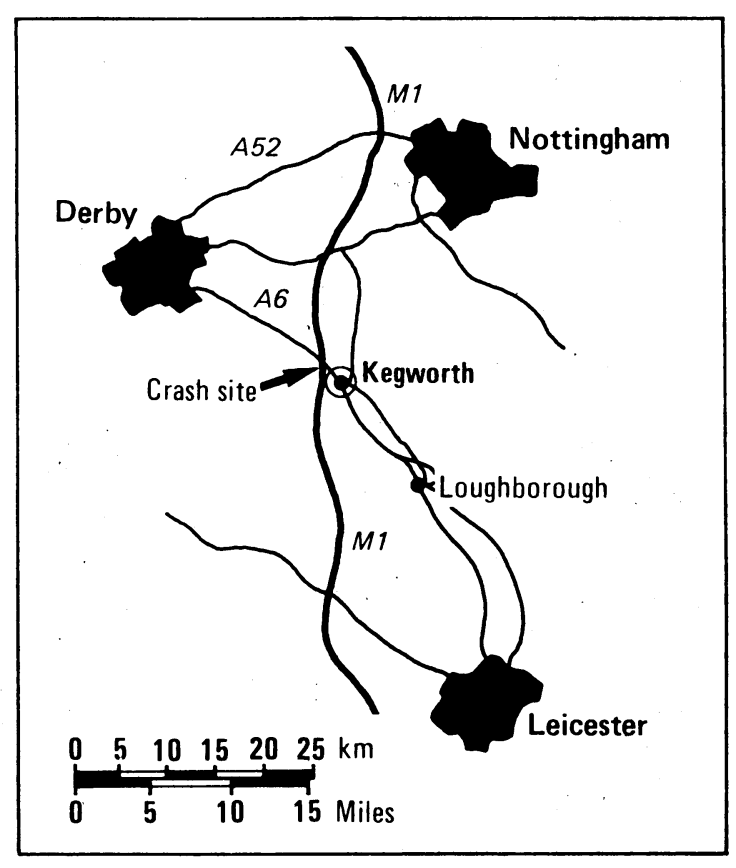

FIG 1-Map of area

radiography the other patients were taken to one of the two receiving wards that had been cleared of their existing patients. (This was achieved by moving the current inpatients to gynaecological and paediatric wards.) In the two receiving wards patients were reassessed by orthopaedic and other appropriate teams and given further resuscitation and their case was given priority if an operation was needed. Patients were reassessed throughout the night. In addition, the orthopaedic teams assessed every patient each subsequent morning. Two patients died within 12 hours after admission of overwhelming multiple injuries and a further two died within three weeks after the accident.

In all, 409 radiological examinations were performed during the night (including computed tomograms and angiograms), and in the first 12 hours 248 units of blood were used -209 units were crossmatched within 150 minutes after the crash. Over the first 48 hours a total of 544 units were cross matched and 481 units used on 27 patients, together with 55 units of fresh frozen plasma and 91 units of platelets. During the first 36 hours 64 operative procedures were performed and two operating theatres were active for all of the week (both from 9 am to well into the night each day) to treat those needing operations. After seven days over 1000 radiological procedures had been undertaken on the victims of the air crash.

Ten days after the Kegworth disaster patients were still undergoing operations, and for many rehabilitation will need to continue for a long time into the 


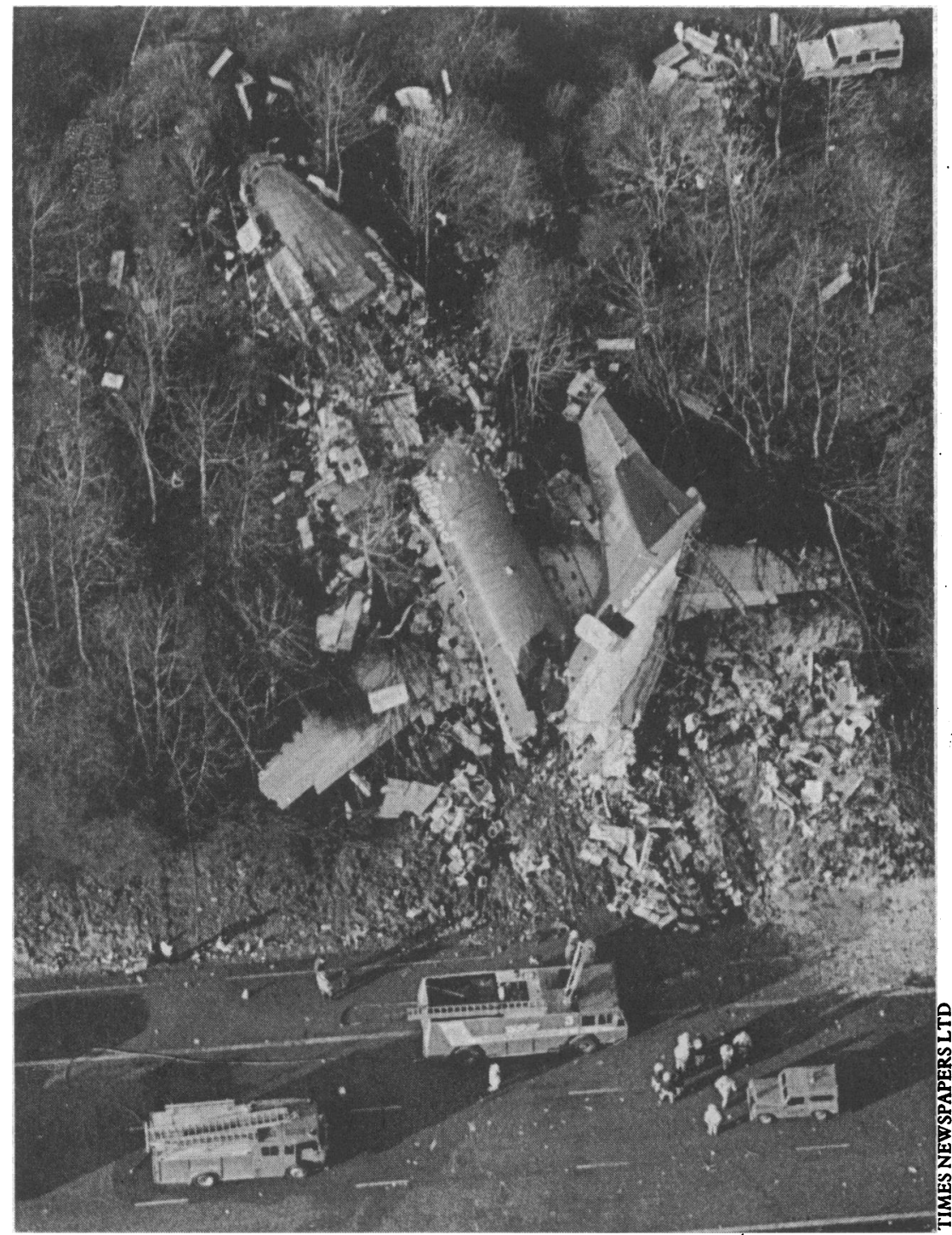

FIG 2-Aerial photograph of aircraft after accident

future. The workload was such that most non-urgent operations for trauma were postponed for two to three weeks. Indeed, the intensive care unit could consider taking on only elective surgical admissions (such as neurosurgical and vascular cases) three weeks after the disaster. By this time 12 patients had been discharged or transferred from the hospital.

\section{Leicester Royal Infirmary}

At Leicester the major accident alert was activated at about $840 \mathrm{pm}$. The flying squad had already been dispatched to the accident scene. The three consultants in accident and emergency medicine were called in immediately; three orthopaedic consultants, four consultant general surgeons, and six consultant anaesthetists were also in the hospital within an hour after the disaster, as well as many junior doctors. Extra nurses and ancillary staff were called in and the various departments made ready to accept the survivors. Beds were made available on two orthopaedic and two general surgical wards.

A consultant surgeon was put in overall charge of the operation and a triage point established in the accident and emergency department. The first patient arrived at $10 \mathrm{pm}$, the patients received being many of those who had been trapped in the wreckage. They were transferred by both ambulance and helicopter from the site of the crash to Leicester. On admission the survivors, although in pain, were remarkably calm, and many had sustained similar combinations of injuries such as dislocated shoulders and leg fractures. All patients were resuscitated in the accident and emergency department and their injuries documented and radiological examinations ordered.

After radiography patients were sent to the recovery area in the accident and emergency department where they were reassessed by one of the orthopaedic consultants. A priority operating list was then drawn up. The more seriously injured patients were sent directly to the intensive care unit; where they could be given further resuscitation and stabilised. From the intensive care unit they were transferred to the recovery area of the theatre block to await operation. Eighty six units of blood were cross matched on the night and 41 units used; the following day 26 units were requested, of which 21 units were used.

On the night two theatres in the main theatre block and the theatre in the fracture clinic were opened. Ten patients required 23 surgical procedures, including evacuation of extradural haematoma and repair of a ruptured bladder, which were performed during the night from $1045 \mathrm{pm}$ to 11 am the next morning. A further six patients were stabilised in splints and plaster and their operations planned for later in the week. Four patients had minor injuries-metatarsal fractures, cuts, and bruises - and did not require an operation. The last patient arrived at 4 am but died in the accident and emergency department of multiple injuries.

During the next week theatre lists were arranged so that the closed injuries could be treated; all the soft tissue wounds were inspected and the treatment of fractures reassessed, requiring 25 procedures on 15 patients.

Currently soft tissue problems such as devitalised areas of skin that require skin grafts continue to occupy surgical time. Three weeks after the accident 13 patients had been discharged home or to their local hospitals for rehabilitation.

\section{Derbyshire Royal Infirmary}

The Derbyshire Royal Infirmary received 25 patients from the crash site over 90 minutes. They were rapidly resuscitated and assessed in the accident and emergency department by casualty, anaesthetic, orthopaedic, and general surgical staff of all grades assembled before the arrival of the first survivors. Three consultant orthopaedic surgeons and five registrars were helped by an equal number of general surgical staff. Consultants and registrars on reserve were in contact by telephone, and it was thought particularly important to ensure a supply of fully rested staff for the next day's work. In keeping with the nature of the disaster the arrival of the more seriously injured patients was delayed. In all cases resuscitation had been started at the scene of the crash and was continued during transit. Only one patient required immediate surgery for life threatening injury, and he was taken directly to the operating theatre. Two patients had minor bruising alone and were discharged. The remaining 22 patients were reassessed after radiography and were transferred to intensive care, theatre reception, and recovery or to one of the two evacuated wards, according to the nature of their injuries. Eight patients were in need of urgent operation and another six patients were operated on within 24 hours. Four of the six operating theatres available were commissioned by one general surgical and three orthopaedic teams. Five other patients were operated on in the next few days. In the first 12 hours 11 patients underwent operation, with 31 procedures being performed, and over 48 hours 49 procedures were completed on 21 patients. Five patients also had procedures performed under local anaesthesia on the initial night. 
The number of staff available allowed those undergoing urgent operations to remain in either intensive care or the operating theatre's recovery area overnight with excellent supervision by nursing, anaesthetic, and medical staff, which released more nursing staff to care for patients on the wards.

The radiology department provided a speedy and efficient service, with 137 radiological examinations performed, including one intravenous urogram and three arch aortograms. No patient required urgent computed tomography. In 12 patients a total of 95 units of blood was cross matched, with only five ultimately being transfused with 53 units. Four units of fresh frozen plasma were also used.

TABLE I - Summary of date from three hospitals dealing with survivors of aeroplane crash

TABLE II-Amount of whole blood used and cross matched and plasma and platelets used in Nottingham, Leicester, and Derby during first 36 hours after crash

\begin{tabular}{lrr}
\hline & No of units \\
\hline $\begin{array}{l}\text { Whole blood: } \\
\text { Used }\end{array}$ & & 596 \\
$\quad$ Within 12 hours & 382 & \\
$\begin{array}{c}\text { From 12 to 36 } \\
\quad \text { hours }\end{array}$ & 214 & \\
$\begin{array}{c}\text { Crossmatched } \\
\text { Within 2.5 hours }\end{array}$ & 209 & 751 \\
$\begin{array}{l}\text { Fresh frozen plasma } \\
\text { Platelets }\end{array}$ & & 59 \\
\hline
\end{tabular}

TABLE III-Major injuries sustained by 82 people who survived first 24 hours after crash. Values are numbers of cases unless stated otherwise

\begin{tabular}{lrr}
\hline Significant head injury & & 35 \\
Lung contusion, etc & & 191 \\
Abdominal trauma & & 5 \\
Fracture & & 191 \\
Skull & 3 & \\
Facial & 3 & \\
Spinal & $20^{\star}$ & \\
Pelvis & $25 \dagger$ & \\
Hip dislocation & 5 \\
Femur & 22 & \\
Knee & 3 \\
Tibia and fibula & 30 \\
Ankle & 17 \\
Talus & 4 \\
Calcaneus & 1 \\
Mid-foot & 4 \\
Metatarsal & 6 \\
Clavicle & 1 \\
Scapula & 6 \\
Dislocated shoulder & 7 \\
Humerus & 8 \\
Radius and ulna & 20 \\
Carpal & 1 \\
Hand & 5 \\
No of people with rib & \\
fractures & 9 \\
\hline
\end{tabular}

^Five with neurological loss. †Ten affecting acetabulum.

\begin{tabular}{lccc}
\hline & $\begin{array}{c}\text { University } \\
\text { Hospital } \\
\text { Nottingham }\end{array}$ & $\begin{array}{c}\text { Leicester } \\
\text { Royal } \\
\text { Infirmary }\end{array}$ & $\begin{array}{c}\text { Derbyshire } \\
\text { Royal } \\
\text { Infirmary }\end{array}$ \\
\hline $\begin{array}{l}\text { No of patients received } \\
\text { No of patients dying: } \\
\text { Within 12 hours }\end{array}$ & 40 & 21 & 25 \\
$\begin{array}{l}\text { Within 3 weeks } \\
\begin{array}{l}\text { No of patients discharged within } \\
\text { three weeks }\end{array}\end{array}$ & 2 & 1 & \\
$\begin{array}{l}\text { No of radiographs within 12 hours } \\
\text { No of procedures: } \\
\text { Within 12 hours } \\
\text { Within 36 hours }\end{array}$ & 12 & 13 & 22 \\
$\begin{array}{l}\text { No of patients having operations: } \\
\text { Within 12 hours }\end{array}$ & 38 & 210 & 137 \\
Within 36 hours & 64 & 23 & 31 \\
\hline
\end{tabular}

$\star$ No within 48 hours.

On the day after the disaster all patients were transferred to one ward, with the exception of four patients who remained in the intensive care unit. This enabled easy management and was appreciated by the patients, who derived considerable communal support. Elective orthopaedic admissions to the infirmary were called for the week mainly because of the high bed occupancy. Routine orthopaedic emergency treatment continued to be carried out the next day-indeed, four hemiarthroplasties for fractured neck of femur were performed on the day after the disaster. Three weeks after the incident three patients remained at the infirmary.

\section{Mansfield and District Hospital}

Two patients were taken to Mansfield and District Hospital, where their fractures of the arms and legs required inpatient treatment.

\section{Discussion}

Table I summarises the data from the three hospitals. Table II shows how much blood was used by the three main hospitals and table II the tally of injuries sustained by the 82 people who survived the first 24 hours after the crash. Thirty of the 191 fractures were compoundindeed, the staff in Nottingham had to send out for more external fixators as it became obvious, early on the Sunday night, that the usually adequate supply of fixators would be rapidly used up by the many patients with bilateral compound fractured tibias. Straumann (GB) was extremely helpful in supplying 12 fixator sets within hours after being telephoned on the Sunday night. The same thing happened in Derby, and fixators were acquired from hospitals in Coventry and Nuneaton. These collated figures are as complete as possible three weeks after the crash and give an impression of the surgical challenge faced by the three hospitals.

A study group (see appendix) has been formed to collect as much data as possible about both the survivors and those who died and to correlate the injuries with the mechanical forces generated in different areas of the aircraft on impact. The group consists of orthopaedic teams from Nottingham, Leicester, Derby, and Belfast, as well as representatives of all other specialties concerned with treating the survivors. The group has already had the benefit of close cooperation with the local coroner and other agencies, enabling it to obtain a clear, early picture of how the injuries were sustained.

All bruising has been documented both photographically and diagrammatically, and at this stage some interesting patterns of soft tissue damage are emerging that are related to the position and tightening of the seatbelts worn. Statistical analysis of these injuries may be extremely rewarding. The pattern of the injuries sustained by survivors in the three different sections of the aircraft seems to vary. The reasons for this are under investigation.

An opportunity such as this, to document so thoroughly the injuries of so many survivors, rarely occurs. We hope to exploit it fully to obtain as much information as possible to further our understanding of how the trauma of surviving an aeroplane crash may be mitigated.

We thank all the staff who helped in gathering information for this article, particularly Mrs Cathy Elliott and Mrs Vicki Price, research assistants, Nottingham. We thank Dr David Banks, Nottingham Health Authority, for initially underwriting the expenses incurred in carrying out the research project. Barclays Bank, Bonfab, AO, Straumann (GB), and Private Patients Plan contributed financially to the project.

\section{Appendix}

NOTTINGHAM, LEICESTER, DERBY AIRCRAFT ACCIDENT STUDY GROUP

As a consequence of the aircraft accident on the 8 January 1989 a study group was set up to research and investigate the injuries. The aims of the study are $(a)$ to identify and document all soft tissue and bony injuries to the crash victims; (b) to analyse the mechanical forces generated by the crash at each seat position; $(c)$ to investigate the probable causes of the injuries sustained; $(d)$ to document the immediate and definitive management of all injuries sustained; $(e)$ to follow up all injured patients for six months and establish the outcome; $f(f)$ to identify the nature and number of missed injuries; $(g)$ to carry out an internal audit of our own performance in looking after crash survivors; $(h)$ to draw relevant conclusions from the study.

The study group has the following composition.

Chairman-Professor W A Wallace (Nottingham).

Research registrar-Mr J M Rowles (Nottingham).

Orthopaedic surgery-Messrs C L Colton and G Kirsh (Nottingham), P G Lunn and J P Martindale (Derby), H I Thomas and D J A Learmonth (Leicester), and J CMcClelland and G R Tait (Belfast).

Thoracic surgery - Mr W E Morgan (Nottingham).

Neurological and spinal injuries - Mr J L Firth, $\mathrm{Mr} \mathrm{J} \mathrm{K} \mathrm{Webb,}$ Dr C J Mumford, and Mr B D White (University Hospital, Nottingham).

Radiology-Dr B J Preston (Nottingham).

Anaesthesia-Dr A J Byrne (Nottingham).

Accident and emergency-Drs A F Dove (Nottingham), M J Allen (Leicester), and P E Pritty (Derby).

General surgery - Mr C S Robertson (Nottingham).

Pathology-Professor J S P Jones (Nottingham).

Research assistants-Mrs V Price and C Elliott (Nottingham). 